\title{
Proximal Migration of Pancreatic Stent A Case Report and Recommendations
}

\author{
Xiao-ping $\operatorname{Pan}^{1}$ \\ ${ }^{1}$ The people's hospital of Wuhai, Inner Mongolia, China \\ Correspondence: Xiao-ping Pan, The people's hospital of Wuhai, Inner Mongolia, China. Tel: 86-131-7123-1000 \\ E-mail: pxp74@sina.com
}

Received: December 30, 2013 Accepted: January 14, 2014 Online Published: November 10, 2014

doi:10.5539/ijb.v7n1p61 URL: http://dx.doi.org/10.5539/ijb.v7n1p61

\begin{abstract}
Background: Pancreatic stents are commonly used in the treatment of pancreatic diseases but can cause many complications, including proximal migration.
\end{abstract}

Case Report: We report a case of a proximally migrated pancreatic stent and how by using duodenal biopsy forceps we successfully removed the shifted stent.

Conclusions: Pancreatic stenting requires high technical skills and the choice of the right stent is a very crucial in the success of the procedure. Once the stent is shifted, biopsy forceps can be used to remove the pancreatic duct stent.

Keywords: pancreatic stent; post-ERCP pancreatitis; complication; migration; prevention

\section{Introduction}

Studies demonstrated the effectiveness of pancreatic stents in preventing post endoscopic retrograde cholangiopancreatography(ERCP) pancreatitis in high-risk patients, shortening hospital stay, and reducing the financial burden of the patient (Fazel, Quadri, Catalano, Meyerson, \& Geenen, 2003; Pan et al., 2011). However, the technique is highly risky and the procedure can be difficult to carry out. It can cause complications such as severe pancreatitis, perforation, bleeding, infections, and early stent migration (Andriulli et al., 2007). The following is a report about a case of proximal migration of pancreatic stent which we encountered during our practice.

\section{Case Description}

Patient A, female, 74 years old, was admitted to the hospital because of a persistent diffusing pain in the right upper quadrant that started 1 month ago. Abdominal ultrasound showed common bile duct stones. Magnetic resonance cholangiopancreatography (MRCP) also confirmed multiple stones in the lower segment of the common bile duct with incomplete biliary obstruction after cholecystectomy. Physical examination revealed normal vital signs, no sclera or systemic jaundice. Abdomen was soft with no varicose veins; there was a severe right upper quadrant tenderness, no rebound tenderness or muscle tension. Liver could not be palpated underneath the rib cage. Lab examination: whole blood cell count, liver and kidney functions and urine amylase were in normal ranges. ERCP was performed 3 days after admission. During the procedure, we found that the patient also presented with duodenal diverticulum we decided on the spot that duodenal endoscopic sphincterotomy, endoscopic common bile duct choledochotomy, endoscopic nasal biliary drainage and pancreatic duct stenting should be performed simultaneously. The chosen pancreatic duct stent was GPSO-5-5 plastic stent from Cook (Bloomington, Indiana, USA). The patient showed little discomfort after the opration, her urine amylase increased transiently after ERCP and returned to normal three days later, while her lipase levels remained normal during all the time. Considering that her state was stable, we removed her nasal drainage one week after the procedure and decided to remove the pancreatic stent 3 months later in order not to cause secondary damage to her pancreatic duct. The patient was then discharged and convalesced at home.

After four months, the patient returned to the hospital to get her stent removed. However abdominal plain radiographs showed that the pancreatic duct stent was displaced towards the pancreatic tail direction. Abdominal ultrasound showed that pancreas was normal in size, the pancreatic duct was not dilated; there was a strong echo at the oancreatic head area. Laboratory tests revealed no abnormalities. It was unavoidable that the patient had to 
undergo another operation to get the stent removed. Considering the difficulty to remove the stent, we prepared balloon catheter, snare, biopsy forceps and other necessary tools. During the operation, ERCP was performed using Olympus TJF-260 electronic duodenoscope to locate the pancreatic duct stent, then biopsy forceps were inserted successfully into the pancreatic duct under X-Ray machine, the forceps grabbed the head of the stent and pulled it out slowly. The operation was completed in 1 hour. The patient presented with symptoms associated with pancreatitis after the operation, we ordered the patient to fast in order to suppress the secretion of pancreatic juice, and also provided antibiotic treatment to her. The patient was recovered in 1 week and was discharged.

\section{Discussion}

Pancreatic stenting is a very effective way in prevent post-ERCP pancreatitis in high rick patients, shortening hospital stay and cost-effective (Fazel, Quadri, Catalano, Meyerson, \& Geenen, 2003). Although its prophylactic effect is well recognized, it may require a separate endoscopy to remove the stent in case of displacement, thus increasing the chance of tissue damage. Experts agreed that in view of pancreatic stenting, we should take the decision more cautiously (Freeman, 2007).

Most stent migrations occur during the early stage of the placement and tend to shift outwards (towards the head of the pancreas). This can cause difficulty in draining pancreatic juice because the displaced stent has lost its function and patient can present apparent symptoms of pancreatitis. We have seen a few case reports on inward stent migration (towards the tail of the pancreas ) which occurred during the later stage of the placement with different causes.

We discussed our case and believed that the main reason for the stent migration was to have inserted pancreatic duct stent too deeply, therefore the outer end of the bracket barb was stuck in the pancreatic duct instead of remaining in the opening of the duct, thus losing its function of prevent the stent moving inwards. As the pancreatic juice flowed outwards the inner end of the stent which was at the tail of the pancreas forced the stent moving inwards, . Also in this patient, the pancreatic duct made a $90^{\circ}$ turn at the head of the pancreas. As a result, the most part of the stent was inside of the curve. This anatomy curve facilitated the inwards shift of the stent.

Pancreatic stenting requires high technical skills, as any small mistake may lead to serious consequences. In this case, the outer stent barb did not open and created conditions for stent to migrate inwards. Therefore, we recommend that surgeons who are going to perform this technique should receive a systematic training to master the operation skills of ERCP, we should standardize the procedure steps, and operate accordingly.Surgical snare, balloon catheter, and biopsy forceps can be used to remove the stent embedded deeply in pancreatic duct.

After the pancreatic stent is removed, patients may show symptoms of acute pancreatitis; this may be caused by the injuries of pancreatic tissue during stent removal. Pancreatic injuries may also occur if the stent is left in the pancreatic duct for more than 4 months, so we should remove the stent as early as possible if the patient's condition permits. After stent removal, patients usually receive post-ERCP nursing, gastrointestinal decompression, antibiotics, liver orotective agents and gastric mucosal-protective agents.

Another important issue is how to choose the right stent. Freeman, Overby, and Qi (2004) adopted a smaller stent $(2 \sim 3 \mathrm{~cm}, 3 \sim 5 \mathrm{~F})$, as this increased the success rate of pancreatic stenting and reduced the risk of stent placement failure. By contrast, a retrospective study by Rashdan et al. (2004) showed that the $3 \sim 4 \mathrm{~F}$ stents performed better than the commonly used $5 \sim 6 \mathrm{~F}$ stents in preventing post-endoscopic retrograde cholangiopancreatography pancreatitis. In our experience, the $3 \mathrm{~F}$ pancreatic stent is difficult to manipulate and is very expensive, whereas the $5 \mathrm{~F}$ stent is more user-friendly. This maybe mainly related to the operator's manipulation skills.

Finally, I recommend that when we use the pancreatic duct stent manufactured by Cook, we can remove the inner end of the stent in order to reduce the damage caused when the stent is pulled out and to prevent inward displacement.

\section{References}

Andriulli, A., Forlano, R., Napolitano, G., Conoscitore, P., Caruso, N., Pilotto, A., ... \& Leandro, G. (2007). Pancreatic duct stents in the prophylaxis of pancreatic damage after endoscopic retrograde cholangiopancreatography: a systematic analysis of benefits and associated risks. Digestion, 75(2-3), 156-163. http://dx.doi.org/10.1159/000106774

Fazel, A., Quadri, A., Catalano, M. F., Meyerson, S. M., \& Geenen, J. E. (2003). Does a pancreatic duct stent prevent post-ERCP pancreatitis? A prospective randomized study. Gastrointestinal endoscopy, 57(3), 291-294. http://dx.doi.org/10.1067/mge.2003.124

Freeman, M. L. (2007). Pancreatic stents for prevention of post-endoscopic retrograde cholangiopancreatography pancreatitis. Clinical Gastroenterology and Hepatology, 5(11), 1354-1365. http://dx.doi.org/10.1016/j.cgh.2007.09.007 
Freeman, M. L., Overby, C., \& Qi, D. (2004). Pancreatic stent insertion: consequences of failure and results of a modified technique to maximize success. Gastrointestinal endoscopy, 59(1), 8-14. http://dx.doi.org/10.1016/S0016-5107(03)02530-6

Pan, X. P., Dang, T., Meng, X. M., Xue, K. C., Chang, Z. H., \& Zhang, Y. P. (2011). Clinical study on the prevention of post-ERCP pancreatitis by pancreatic duct stenting. Cell biochemistry and biophysics, 61(3), 473-479. http://dx.doi.org/10.1007/s12013-011-9230-4

Rashdan, A., Fogel, E. L., McHenry Jr, L., Sherman, S., Temkit, M. H., \& Lehman, G. A. (2004). Improved stent characteristics for prophylaxis of post-ERCP pancreatitis. Clinical Gastroenterology and Hepatology, 2(4), 322-329. http://dx.doi.org/10.1016/S1542-3565(04)00062-X

\section{Copyrights}

Copyright for this article is retained by the author(s), with first publication rights granted to the journal.

This is an open-access article distributed under the terms and conditions of the Creative Commons Attribution license (http://creativecommons.org/licenses/by/3.0/). 